Revista de Economia Política, vol. 20, $n^{\circ} 1$ (77), pp. 146-157, janeiro-março/2000

\title{
Notas sobre a Reforma Previdenciária Brasileira no Contexto do Neoliberalismo e da América Latina*
}

\author{
Note on the Brazilian Social Security Reform in the \\ context of neoliberalism and of Latin America
}

ROSA MARIA MARQUES*

RESUMO: Este artigo tem um duplo objetivo. Primeiro, pretendemos discutir o que está em jogo quando a previdência social pública é alterada para sistemas privados com base em economias individuais. Segundo, nosso objetivo é analisar por que as reformas neoliberais são aceitas com mais facilidade nos países da América Latina (com exceção do Brasil) do que nos europeus.

PALAVRAS-CHAVE: Pensões; reforma previdenciária; sistema previdenciário; privatização da seguridade social.

ABSTRACT: This paper has a double purpose. First, we intend to discuss what is in game when the public social security is changed for private systems based on individual savings. Second, we aim to analyze why the neoliberal reforms are accepted easier in the Latin American countries (with exception of Brazil) than in European ones.

KEYWORDS: Pensions; pension reform; pension system; privatization of social security. JEL Classification: J26; H55; J14.

As propostas de reforma dos sistemas de proteção social, de cunho neoliberal, encontram na América Latina um ambiente particularmente favorável. Enquanto nos países europeus as mudanças implementadas, embora importantes, não chegam a desfigurar a organização e os princípios que nortearam a construção do Welfare State, os avanços do neoliberalismo no campo da proteção social nesse continente têm sido bastante significativos.

O que está em jogo quando se substitui os sistemas de proteção social públicos e de repartição, por sistemas privados e de capitalização? A que projeto de sociedade se vinculam essas duas alternativas? Quais seriam os fatores que explicam essa relativa "facilidade" de implementação das reformas neoliberais em nosso

\footnotetext{
* Professora assistente doutora do Departamento de Economia da Pontifícia Universidade Católica de São Paulo - PUC/SP, São Paulo/SP, Brasil. E-mail: rosamkmarques@gmail.com.
} 
continente? Por que, mesmo assim, observam-se diferenças de conteúdo entre as reformas indicadas na América Latina? Por que a proposta de reforma do governo brasileiro não propôs sua privatização? Essas e outras são as questões que este texto procura responder.

Para isso, analisam-se, na primeira parte, os principais aspectos e características dos regimes de repartição e de capitalização, que fundam os sistemas públicos e privados. É dada especial atenção a como essas formas de organização da proteção social pensam a relação entre o social e o indivíduo. A seguir, na segunda parte, é destacada a diferença entre as reformas implementadas em alguns países na América Latina e a proposta encaminhada pelo governo no Brasil. Finalmente, a título de conclusão, são apontados os principais itens abordados no artigo.

\section{REGIME DE REPARTIÇÃO X REGIME DE CAPITALIZAÇÃO}

\section{Os fundamentos do regime de repartição1}

No regime organizado a partir da lógica da repartição, os trabalhadores em atividade financiam, mediante sua contribuição e de seus empregadores, as aposentadorias e demais benefícios na expectativa de que, no futuro, isso lhes seja também provido, com base na contribuição de gerações futuras de trabalhadores. Dessa forma, estabelecem-se "laços de solidariedade" entre gerações de trabalhadores e mesmo entre os membros de uma mesma geração. Como diz Van Parijis, o que concede a forte solidariedade presente nos regimes de repartição simples, é o fato de ninguém saber, ex-ante, se terá vantagem ou desvantagem ao estar contribuindo ao sistema. Sua organização é estruturada a partir do véu da ignorância (Van Parijis, 1994).

Além dessa solidariedade, é possível se destacar outra, que deriva da natureza assumida pelas contribuições nos regimes de repartição. Para se compreender essa natureza, é preciso lembrar que, nas sociedades que organizam a proteção social dessa forma, o salário é composto de duas partes: um salário direto e uma contribuição social, paga pelo empregador. A primeira é fruto de negociações entre trabalhadores e empresa(s) ou de regulamentação, como é o caso do salário-mínimo, sendo apropriada pelo trabalhador individual. Já a contribuição social, definida pela legislação, converte-se imediatamente em benefícios, sem que se configure, em

\footnotetext{
${ }^{1}$ Enquanto processo histórico, a construção dos sistemas de proteção social, financiados a partir do trabalho assalariado e organizados em regime de repartição, devem muito aos trabalhadores. Apesar de, num primeiro momento, terem sido utilizados como instrumento para o assalariamento dos despossuídos, e, no pós-guerra, terem assumido um papel funcional na reprodução da acumulação fordista, suas bases e desenvolvimento foram determinadas pelo grau de organização independente alcançada pelos trabalhadores. Em particular o Welfare State foi provocado pela a franca iniciativa assumida pelos trabalhadores ao final da Segunda Guerra (Marques, 1997).
} 
momento algum, em poupança. Dessa forma, tanto o salário direto como a contribuição do empregador constituem um fluxo.

A contribuição paga pelas empresas, bem como a de responsabilidade dos trabalhadores, nasce no exato momento em que se configura o trabalho assalariado, não havendo como separá-la de sua remuneração. Além disso, como o valor das contribuições mantém uma relação com o salário, mesmo no caso da existência de teto, sua transformação imediata em benefícios lhe concede o caráter de salário socializado.

No regime de repartição, todos os trabalhadores, independentemente de seu nível de salário e poupança, são vistos de uma forma homogênea, isto é, como contribuintes e beneficiários potenciais. Mais do que isso, mesmo aqueles que estão recebendo auxílio-doença ou seguro-desemprego são vistos como contribuintes, muito embora não lhes seja exigida nenhuma participação enquanto estiverem nessa condição ${ }^{2}$. Desse modo, o status de contribuinte deriva de sua condição de trabalhador.

Essa maneira de entender os regimes de repartição permite se olhar os benefícios assistenciais de maneira não usual. No interior de todos os sistemas estruturados com base no trabalho assalariado, sempre houve a presença de um número significativo de benefícios que poderiam ser qualificados como assistenciais, isto é, que são concedidos sem a exigência de prévia contribuição. Hoje, inclusive, tendo em vista o aprofundamento da pobreza e o nível de desemprego, cresce a participação desses benefícios no total das despesas de proteção social nos sistemas do mundo desenvolvido.

Do ponto de vista da lógica de seguro, a presença desses programas é entendida como uma distorção, pois só reconhece como legítimo o benefício que está fundado numa certa quantidade de contribuições. E por essa razão que muitos defendem, no Brasil, que o mínimo velhice, por exemplo, deva ser financiado mediante recursos de impostos, e não das contribuições de empregados e empregadores.

Contudo, se partirmos do pressuposto de que o trabalho - base sobre a qual se calculam as contribuições - é a fonte de criação da riqueza e o instrumento do reconhecimento social dos indivíduos na sociedade capitalista, as contribuições devem financiar inclusive os programas assistenciais. Desse modo, o caráter de salário socializado das contribuições estaria sendo aplicado no seu sentido mais amplo, pois a socialização decorre não apenas do uso indistinto por seus beneficiários, mas do entendimento de que seus recursos são produzidos pelo trabalhador coletivo. E esse trabalhador é formado também pelo exército de reserva, clientela que demanda tanto os benefícios assistenciais como o seguro-desemprego ${ }^{3}$.

\footnotetext{
${ }^{2}$ No caso brasileiro, não se estabelece essa relação com o desempregado, pois esse seguro e financiado através do faturamento.

${ }^{3}$ Em vários sistemas, quando o trabalhador esgota o período de concessão do Seguro-desemprego passa a receber benefícios assistenciais. É preciso lembrar, ainda, que os demais beneficiários da assistência constituem também trabalhadores, que ocupam ou ocupavam os piores empregos.
} 
A incorporação dessa categoria no conceito de trabalhador coletivo deriva do próprio entendimento que a sociedade salarial tem sobre ela: são pessoas que não encontram emprego, embora o busquem e dele precisem; são pessoas que, embora não queiram, recebem remuneração aquém da considerada digna pela sociedade. Assumindo-se que os baixos salários e a inexistência de emprego para todos é função de uma determinada combinação de nível de produtividade e de relações entre capital e trabalho ${ }^{4}$, as ações individuais de empresários, que despedem ou pagam baixos salários, passam a ser responsabilidade do conjunto das empresas. O lado perverso dessas ações, isto é, o desemprego e a necessidade de auxílio para complementação de renda, é assumido pelo conjunto dos empresários, através das contribuições. Dessa forma, o salário, ao ser composto também pelas contribuições, reconhece, indistintamente, o trabalho dos ocupados e dos não-ocupados, assim como reconhece como igual o trabalhador qualificado e o desqualificado. Esse reconhecimento funda a solidariedade do trabalhador coletivo.

A partir desse entendimento, a permanência do salário como base de financiamento da proteção social assume importância central: é a garantia que todos terão, de uma maneira ou de outra, renda de substituição definida. Mais do que isso, é a garantia que mesmo os desempregados terão um reconhecimento social decorrente de sua posição de beneficiários, posto que esses são financiados por salário socializado, produzido pelo trabalhador coletivo.

\section{Os fundamentos do regime de capitalização}

Nos anos 80, com o aprofundamento da crise financeira dos sistemas de proteção social, com o aumento substantivo do desemprego e com o acirramento da concorrência intercapitalista, ganhou força a ideia de restringir a ação do Estado ao mínimo absolutamente necessário. Segundo o pensamento neoliberal, os sistemas atuais de proteção social deveriam ser desmantelados, de maneira que a provisão para a aposentadoria e a doença seria formada exclusivamente a partir do esforço individual de cada um, cabendo ao Estado apenas o suporte aos menos favorecidos, através da concessão de benefícios mínimos. Na esfera da saúde, a proposta de garantia de uma cesta básica (de serviços e ações) passou a ser defendida ao lado da introdução do teste de meios, como critério de acesso a seu sistema público.

A presença mínima do Estado não se restringe ao campo da proteção social. A rigor, aqueles que a advogam, consideram que tudo aquilo que impede o livre jogo das forças do mercado é nefasto para economia e impede o desenvolvimento do bem estar e a liberdade dos indivíduos. Sendo assim, defendem o afastamento do Estado de atividades produtivas, a eliminação de pisos salariais e demais aspectos da regulamentação do trabalho. Quanto a esse último item, propõem, no máximo,

\footnotetext{
${ }^{4}$ Para uma interessante descrição histórica e conceitual da categoria desempregado, ver Comte (1995).
} 
a introdução da negociação por empresa, em substituição ao acordo coletivo defendido pelos trabalhadores.

$\mathrm{Na}$ esfera social, a intervenção do Estado - ao exigir a obrigatoriedade da contribuição de empresas e trabalhadores - e ao fundar a concessão de benefícios em princípios redistributivistas - é considerada antieconômica, ineficaz e ineficiente. Segundo o pensamento neoliberal, as contribuições desincentivam o investimento, pois oneram a contração da força de trabalho. A ineficácia, por sua vez, derivaria tanto da condição de quase monopolista que assume o Estado, como do fato de ele ser pressionado por grupos organizados para a concessão de serviços e benefícios, tais como categorias de trabalhadores e grupos de interesses vinculados à saúde. Nesse particular, consideram que seria melhor que a demanda social fosse exercida por consumidores atomizados e que a oferta fosse passível de concorrência. A ineficiência, por sua vez, decorreria do fato de a pobreza não ter sido eliminada, a despeito da existência do Welfare State, e da compreensão que os benefícios assistenciais tendem a acomodar o trabalhador à sua condição de carente, desestimulando a procura por trabalho ou melhor salário.

A partir dessas premissas, o pensamento neoliberal defende que urge reconstituir o mercado, a concorrência e o individualismo no campo social. Para ele, os serviços e ações atinentes à proteção social devem ser deixados nas mãos da família, da comunidade e do mercado. Nessas circunstâncias, o Estado apenas garantiria proteção para aqueles absolutamente carentes que, por seus meios, não teriam como comprar serviços no mercado. Em termos de geração de serviços, caberia, ainda, ao Estado, tudo aquilo que o setor privado da economia não quisesse ou não pudesse produzir, e tudo aquilo que tivesse grande externalidade, tal como campanhas de vacinação.

No caso específico da aposentadoria, sua privatização pressupõe a capitalização do esforço individual de cada um, de forma que, via de regra, o valor do benefício a ser recebido depende do montante poupado e da rentabilidade alcançada do fundo a que é integrante. Dessa maneira, o grau de incerteza quanto ao nível de cobertura, que será garantido quando da retirada do mercado do trabalho, é absolutamente acentuado.

Chesnais (1997), ao analisar o duplo caráter dos fundos de pensão, chama atenção para a instabilidade presente nesse tipo de organização da proteção social. Inicia lembrando que, embora os fundos privilegiem particularmente dois tipos de aplicação, ou seja, as obrigações emitidas pelo Estado e o mercado de ações, há uma forte concentração nessas últimas. Os fundos de pensão americanos, por exemplo, têm entre 45 e $50 \%$ de seus ativos sob a forma de ações; os fundos britânicos, $65 \%$.

A seguir, defende que a bolsa apenas "capta os fluxos de riqueza criados em outra parte no sistema econômico, nacional ou mundial” (Chesnais, 1997: 14), não criando, ela mesma, nenhuma riqueza. Também lembra que, a qualquer sinal de crash, os administradores dos fundos liquidam suas posições nos mercados de obrigações e ações. Dessa forma, a capacidade dos fundos de pensão garantir proteção social, ainda que para o indivíduo, torna-se extremamente incerta.

Como lembra esse autor, os fundos de pensão têm, assim, uma natureza dupla. 
De um lado, são o resultado acumulado de contribuições calculadas sobre salários e rendas e seu objetivo explícito é assegurar uma aposentadoria decente e estável quando o trabalhador se retirar da vida ativa. De um outro lado, desde que o montante acumulado da poupança ultrapasse um certo nível, os fundos tomam o lugar de categoria de instituições financeiras não bancárias, cuja função é fazer frutificar um montante elevado de capital-dinheiro, conservando sua liquidez e maximizando seu rendimento. Sua natureza econômica muda assim radicalmente, e os contribuintes assalariados, assim como uma parte das famílias, passam a ser refém do capital financeiro (Chesnais, 1997: 14). Dessa forma, comparada à proteção social garantida pelos regimes de repartição, a privada é mais incerta e instável.

Ademais, a organização da proteção social com base na capitalização individual ou através dos planos de saúde elimina qualquer traço de direito social, de universalidade, de solidariedade e de redistribuição, presente no Welfare State. O acesso e o nível de proteção tornam-se fortemente definidos pela renda do indivíduo. No caso dos cuidados com a saúde, as consequências são ainda mais nefastas, pois permite a quebra do princípio da integralidade, tão cara a qualquer sistema público de saúde. Em outras palavras, ficam apenas garantidos os cuidados e os níveis de atenção previstos no plano de saúde a que a renda do trabalhador permitiu se filiar.

Além disso, a privatização da proteção social significa transformar seus serviços e ações em mercadorias, destruindo qualquer possibilidade de dissociação entre o benefício recebido e a contribuição paga pelo trabalhador ${ }^{5}$. Nesse particular, é interessante ter presente o imenso interesse do capital no desenvolvimento de uma proteção social privada, organizada com base no regime de capitalização. A razão de todo esse interesse reside no fato de as atividades públicas relacionadas à cobertura do risco velhice e doença abarcarem volume significativo de recursos.

Somente as de responsabilidade do governo federal brasileiro, em 1997 ficam perto de $10 \%$ do PIB. Para se dimensionar o real tamanho desse mercado, restaria ainda agregar as despesas realizadas pelos estados e municípios. Essas são sabidamente bastante levadas no campo previdenciário e, no caso da saúde, representam mais de $10 \%$ do orçamento de vários municípios do país. Levando-se em conta o volume de recursos envolvidos, não há dúvida que, principalmente em época de baixo crescimento da economia, a proteção social começa a ser vista como um excelente campo para a acumulação do capital.

Nesse sentido, a implementação da proposta neoliberal, no tocante à proteção social, tem um duplo objetivo:

- Criar novos espaços para a acumulação de capital, carreando para a esfera privada volume considerável de recursos que atualmente não é objeto de formação de lucro;

- Propiciar condições de lucratividade mais favoráveis nas atividades já existentes.

\footnotetext{
${ }^{5}$ No regime de repartição, quanto mais universal e redistributivista, mais desmercantilizado são seus benefícios e serviços.
} 
Em relação ao resto do mundo, a América Latina é a região que mais levou adiante a reforma de seus sistemas de proteção social. Entre elas, a mais emblemática é, de longe, a promovida no Chile.

Nesse país, em 1981, foram abolidos todos os encargos sociais das empresas, passando a proteção social a ser financiada exclusivamente pelas contribuições dos trabalhadores, que são administradas por fundos privados. Como se trata de regime individual de capitalização, a provisão realizada por ele durante sua vida ativa deve lhe permitir ter acesso a uma renda mensal junto a uma seguradora, no momento da aposentadoria. Contudo, segundo vários relatórios, número significativo de trabalhadores não consegue, através de seu esforço individual, garantir a manutenção do valor mínimo de renda definido pela sociedade chilena. Dessa forma, o Estado, apesar da privatização do sistema de proteção social, se vê obrigado a prover esse benefício mínimo ${ }^{6}$.

$\mathrm{Na}$ esteira da reforma chilena, vários outros países modificaram substancialmente seus sistemas 7 . Entre eles se destacam o Peru, a Colômbia, a Argentina e o México, mais recentemente. A título de informação, vale destacar que neste último país a privatização teve início pelo acidente de trabalho. Trata-se de risco mais facilmente administrável, com grandes possibilidades de interesse pelo setor priva$\mathrm{do}^{8}$. No Brasil, no momento em que este artigo estava sendo redigido, a matéria ainda estava sendo objeto de discussão pelo Congresso Naciona19.

A característica básica que unifica essas reformas, com exceção da em pauta no Brasil, é a privatização da proteção social. No lugar de sistemas regidos por repartição simples, financiados por contribuições de empresas e de trabalhadores, introduz-se a capitalização individual, desonerando totalmente as empresas da responsabilidade de cuidar dos riscos a que estão sujeitos seus trabalhadores.

Vale notar que não é em todos esses países que a adesão ao novo regime pode ser considerada um sucesso. No caso da Argentina, por exemplo, não é significativo o número de pessoas que aderiram ao novo sistema. Ao que parece, ao se constituir a adesão facultativa, os governos têm enfrentado dificuldades em demonstrar aos trabalhadores que o novo sistema é "superior" ao anterior, isto é, em relação aquele organizado e administrado pelo Estado.

De qualquer modo, as propostas de cunho neoliberal, que substituem a soli-

\footnotetext{
${ }^{6}$ A poupança do trabalhador é transferida para o Estado e este concede o benefício. A rigor, o Estado passa a custear a diferença entre o valor do piso e a renda possível de ser concedida com base em cálcu10s atuariais aplicados sobre poupança do trabalhador.

${ }^{7}$ Vale lembrar que os demais países aprenderam com a experiência chilena, de modo que não introduziram, no novo sistema, o direito a benefício mínimo (piso). São sistemas que primam, antes de tudo, pela contribuição definida no lugar de benefício definido.

${ }^{8}$ Sobre a reforma mexicana, ver Laurell (1997).

${ }^{9}$ Os deputados estavam apreciando e votando os destaques.
} 
dariedade pela lógica individual, enfrentam dificuldades de aceitação e implementação quanto mais centralizado e universal for o regime de solidariedade e quanto maior a experiência acumulada. Isso explica por que a reforma chilena foi tão facilmente implementada. Além da situação política que impedia a reação organizadas dos trabalhadores, o sistema anterior era fragmentado e pouco universal.

No Brasil, que paga mensalmente 17,5 milhões de benefícios, onde, no que se refere aos trabalhadores do mercado formal de trabalho, foi criado um sistema único, é difícil imaginar que o governo possa promover o desmonte do que existe e, no lugar, implantar um sistema privado. A condição para isso seria desconsiderar o pagamento desses 17,5 milhões de beneficiários. Levando em conta que as contribuições das empresas representam dois terços da arrecadação, não poderia o sistema honrar seus compromissos apenas com o esforço dos trabalhadores. A hipótese de o Estado vir a substituir as empresas no financiamento também está descartada, dado que a redução e controle do gasto público é um dos objetivos do atual governo.

No caso brasileiro, a proposta de reforma, que acabou sendo encaminhada pelo governo, não propõe uma alteração radical do sistema previdenciário. Embora apresente claros indícios de descontinuidade em relação ao conceito de seguridade introduzido na Constituição de 1988, não altera a forma de organização e a cobertura.

Assim sendo, a Previdência continua a ser financiada por contribuições de empregados e empregadores e o produto de sua arrecadação a ser repartido entre os beneficiários. Por outro lado, é mantido o piso de um salário-mínimo e não há alteração nas regras de acesso aos benefícios, a não ser as relativas a aposentadoria, eliminando a aposentadoria por tempo de serviço e extinguindo as aposentadorias especiais para diversas categorias de trabalhadores ${ }^{10}$.

Vale lembrar que, no momento da negociação com as centrais sindicais, no verão de 1995, não houve discordância em relação à eliminação da aposentadoria por tempo de serviço. A única divergência ficou por conta dos critérios de acesso a serem definidos para concessão de aposentadoria. Ao final da discussão, a proposta do governo de exigir uma certa idade (entre 58 e 60 anos, indistintamente para homem e mulher) para o segurado requerer o benefício, foi substituída pelo tempo de contribuição (35 anos para homem e 30 para a mulher). O critério de idade foi reintroduzido quando da discussão da matéria no Senado, mas foi, posteriormente, rejeitado pela maioria dos deputados na votação da Câmara. Considerando que esse item da reforma é entendido como fundamental pelo governo federal, não é de se estranhar se a matéria voltar a ser discutida no próximo exercício.

Em termos financeiros, a eliminação da aposentadoria por tempo de serviço não altera substancialmente a situação das contas da Previdência Social no curto prazo. Ademais, é preciso se levar em conta também as regras de transição, que contemplam em parte a expectativa de direito de quem já contribui para o sistema.

10 A eliminação das aposentadorias especiais é unânime entre os especialistas. 
Sendo assim, a redução da taxa de incremento da despesa com esse tipo de benefício ocorrerá lentamente.

Para efeito do que se está analisando nesse artigo, mais do que verificar o provável impacto financeiro da reforma, interessa discutir se a implementação dessa mudança altera o caráter do sistema previdenciário brasileiro. Para isso é preciso perguntar quem perde com essa reforma. Em outras palavras, qual o impacto, em termos de proteção, da substituição do tempo de serviço por tempo de contribuição?

Para os trabalhadores, que sempre estiveram vinculados ao mercado formal de trabalho, a adoção do tempo de contribuição em nada altera sua situação. Além disso, essa proposta, comparada à de idade de 60 anos, é mais justa, pois possibilita que o trabalhador que começa a contribuir mais cedo também se aposente mais cedo. Os que perdem com a implantação do tempo de contribuição são, certamente, os trabalhadores que, durante a vida ativa, na parte ou no todo, exercem atividade junto ao mercado informal de trabalho. São os trabalhadores dos empresários que vivem à margem das leis trabalhistas ou que, simplesmente, deixam de recolher as contribuições.

Segundo o plano de benefícios ainda vigente, esses trabalhadores podem requerer aposentadoria plena por tempo de serviço, desde que comprovem terem trabalhado durante 35 anos (homem) e terem efetuado noventa contribuições (até ser atingido o limite de 180 contribuições, a lei atual adiciona seis meses de contribuição a cada ano). Para os que não conseguem preencher a exigência, em termos de tempo de serviço, ainda resta a possibilidade de se aposentarem por idade, precisando, no entanto, comprovarem a mesma quantidade de contribuições.

Comparando as condições atuais de acesso à aposentadoria com a exigência de comprovação de 35 anos de contribuição, não resta dúvida que os trabalhadores do mercado informal ficarão à margem da proteção da Previdência básica. Além disso, caso o ônus da comprovação das contribuições recaia sobre o trabalhador, mesmo os inseridos no mercado formal poderão ter dificuldades para requererem sua aposentadoria.

Por outro lado, a introdução do critério de idade pode tornar ainda mais desigual o tratamento dado aos segurados da previdência, pois é sabido que o trabalhador de mais baixa renda ingressa mais cedo no mercado de trabalho. Desse modo, é perfeitamente possível se imaginar situações em que ocorra o cumprimento do tempo de contribuição sem que haja preenchimento do requisito da idade mínima. Nesses casos o trabalhador continuará a trabalhar, até atingir a idade exigida.

A introdução de qualquer um desses critérios, mesmo que corretas do ponto de vista atuarial, fará da previdência social cada vez mais um seguro, distanciandoa de seu objetivo de prover a proteção ao cidadão brasileiro. Poderá, certamente, conceder aposentadoria e pensão para os trabalhadores com carteira assinada, mas excluirá os demais.

O que talvez os proponentes da reforma tenham esquecido é que a baixa exigência de contribuições para a aposentadoria espelhava-se no reconhecimento das 
características do mercado de trabalho brasileiro, onde a participação do informal sempre foi significativa. E bem verdade que, no momento da definição dos atuais critérios de acesso, havia o entendimento que esse mercado tendia a diminuir cada vez mais, dada a dinâmica do trabalho nos anos 70 . Hoje, pelo contrário, verificase o crescimento da importância dos trabalhadores sem carteira assinada e dos autônomos no total dos ocupados.

Desse modo, o sistema previdenciário brasileiro, para cumprir sua função de proteção social, foi construído com um duplo caráter: de seguro e de assistência. E era a existência de um mercado de trabalho formal em expansão que permitia seu financiamento.

No momento em que essa forma de financiamento começa a apresentar problemas — a média da arrecadação dos quatro primeiros meses de 1998 é igual à média arrecadado no ano de 1996 e os déficits são recorrentes — aponta-se a reforma como a única saída para superar os problemas financeiros apresentados pela Previdência Social. Mas será que a única alternativa existente é aquela que prevê a exclusão de trabalhadores de sua proteção?

Uma solução, certamente, passaria pela formalização do mercado de trabalho. A outra seria entender o esforço contributivo faltante como de responsabilidade do Estado, tal como fazem vários países europeus. Essa última alternativa, contudo, além de exigir um aporte significativo de recursos, iria contrariar o propósito do governo brasileiro de conter o gasto público.

A opção da formalização do mercado de trabalho não apresenta, contudo, problemas menores. Além da tradicional luta para que os empresários formalizem a relação com seus empregados, é preciso que a sociedade encontre formas de regulamentação apropriadas que contemplem a terceirização e respondam ao atrativo que o mercado dito informal tem se constituído para parcela dos trabalhadores.

De qualquer maneira, a reforma atualmente em discussão no Brasil não se apresenta igual às já realizadas nos demais países da América Latina. Não se está discutindo a substituição do sistema público por outro, privado.

A hipótese explicativa aqui defendida é que o grau de centralização, de universalização e de institucionalização do sistema brasileiro impede que uma mudança radical seja realizada. Não se trata, portanto, tal como na França, de uma situação derivada da força dos trabalhadores organizados e do papel que outros segmentos da sociedade atribuem ao Welfare State. Trata-se de uma restrição institucional e financeira que somente poderia ser eliminada caso não estivéssemos em uma democracia. O preceito dos direitos adquiridos, mesmo no seu sentido restrito, impede a privatização de um sistema que conta, hoje, com mais de 17,5 milhões de trabalhadores recebendo todo o tipo de benefícios.

Dada essa restrição, a abertura de mercado para os fundos de pensão abertos, no Brasil, deve passar necessariamente pela diminuição do teto de contribuição e de concessão de aposentadoria (hoje igual a dez salários-mínimos). A redução do teto de dez para cinco ou três salários-mínimos já será suficiente para fomentar a estruturação de fundos de pensão voltados principalmente para a classe média brasileira. 
Nesse sentido, a privatização da previdência social pública não somente é inviável como desnecessária. O que a redução do teto irá provocar - aplicada à realidade salarial brasileira - é a criação das "demais camadas" que formam os sistemas de proteção dos países desenvolvidos, isto é, aquelas que estão relacionadas aos fundos de pensão. Talvez a inovação que a proposta brasileira introduza, seja tornar o ingresso em um fundo de pensão obrigatório, o que contraria as experiências internacionais.

\section{CONSIDERAÇÕES FINAIS}

A formação dos sistemas de proteção social está estreitamente vinculada ao processo de construção da sociedade salarial. Embora o movimento dos trabalhadores tenha, principalmente nos países europeus, obrigado a que o Estado se responsabilizasse, em última instância, pelos riscos sociais, a construção dos sistemas de proteção social foi fundamental para o próprio capital. No Brasil, a literatura especializada é, nesse particular, unânime quanto ao papel que a estruturação da Previdência e da Saúde Pública jogou na construção da oferta de trabalho para a indústria. Mais do que isso, auxiliou no disciplinamento dos trabalhadores e na formação e manutenção da demanda.

A partir da década de 80, no entanto, no mundo desenvolvido, aquilo que antes era "funcional" para o capital passa a ser visto como um grande obstáculo. Segundo os neoliberais, os sistemas de proteção social, na medida em que pressupõem a participação das empresas em seu financiamento, impedem que a lucratividade volte aos níveis dos anos 60 e são um dos elementos explicativos do desemprego.

As propostas de privatização da proteção social, no entanto, têm sofrido forte resistência nos países europeus e têm mais facilmente encontrado guarida em países da América Latina. Isso denota que, embora os sistemas de fato enfrentem problemas sérios de financiamento, decorrentes do envelhecimento da população, do aumento do gasto com saúde e do nível de desemprego, a sociedade, se assim quiser, tem como firmar novo pacto que viabilize a criação dos postos de trabalho necessários e o financiamento da nova realidade. Para isso, no entanto, seria necessário que a lógica do pensamento neoliberal fosse abandonada, isto é, aquela que pretende recompor a lucratividade das empresas a partir da redução de custos promovida pela destruição das conquistas dos trabalhadores

Por outro lado, a reação manifestada pelos trabalhadores europeus às tentativas de reforma dos sistemas de proteção social, particularmente pelos franceses, indica que, em matéria de proteção social, nada está ainda definido. Os contornos futuros dos sistemas vão depender da histórica de cada país e, principalmente, da capacidade de luta dos trabalhadores. O que fica claro é que, não há, como querem fazer entender os neoliberais, nenhum modelo de proteção social associado ao que está sendo chamado de globalização. Antes de ser o resultado de uma tendência natural, a substituição dos sistemas públicos por sistemas privados é uma propos- 
ta que visa ampliar o espaço de acumulação de capital e criar condições mais favoráveis para a lucratividade das empresas.

No caso da América Latina, chama atenção a reforma brasileira ora em discussão. A proteção social dela derivada, embora proponha a eliminação de direitos de certas categorias de trabalhadores e abandone a perspectiva mais ampla de proteção que sempre foi seu traço característico (garantia a universalização da cobertura mesmo com um mercado de trabalho informal significativo), ainda se propõe a ser organizada segundo os princípios anteriores. O regime previsto continuará público e de repartição simples. A hipótese aqui defendida é que, além da resistência dos trabalhadores às reformas - que no caso brasileiro não foi tão efetiva - o grau de institucionalização e universalização impede sua substituição por um regime privado, pelo menos nos marcos da democracia.

Mais do que isso, entende-se que, no caso brasileiro, a criação e desenvolvimento dos fundos de pensão abertos não necessitam que ocorra a privatização do sistema público. E suficiente que seja realizado o rebaixamento do teto dos benefícios/contribuições.

\section{REFERÊNCIAS}

CHESNAIS, F. (1997) “Demain les retraites à merci des marchés”, Le Monde Diplomatique. Paris, abril.

COMTE, M. “Três milhões de desempregados”, in BESSON, J. L. (org.) A ilusão das estatísticas. São Paulo, UNESP, 1995.

LAURELL, A. C. (1997) “La reforma contra la salud y la seguridad social”. México, Ediciones Era. MARQUES, R. M. (1997) A Proteção social e o mundo do trabalho. São Paulo, Bienal. 